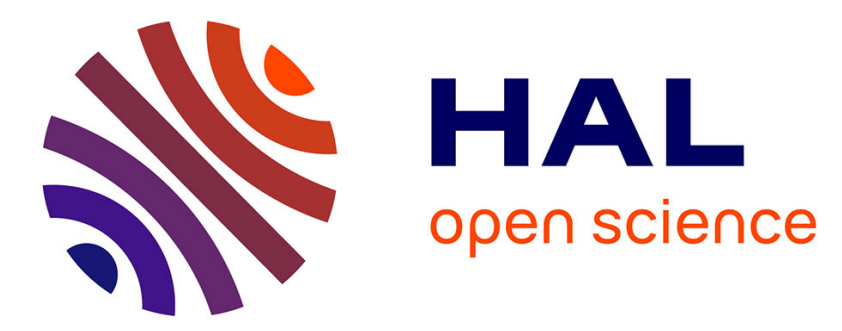

\title{
Vessel Identifications Tags for Open or Laparoscopic Associating Liver Partition and Portal Vein Ligation for Staged Hepatectomy
}

\author{
Raffaele Brustia, Olivier Scatton, Fabiano Perdigao, Sanaa El-Mouhadi, \\ Francois Cauchy, Olivier Soubrane
}

\section{To cite this version:}

Raffaele Brustia, Olivier Scatton, Fabiano Perdigao, Sanaa El-Mouhadi, Francois Cauchy, et al.. Vessel Identifications Tags for Open or Laparoscopic Associating Liver Partition and Portal Vein Ligation for Staged Hepatectomy. Journal of The American College of Surgeons, 2013, 217 (6), pp.e51-e55. 10.1016/j.jamcollsurg.2013.08.020 . hal-02328885

\section{HAL Id: hal-02328885 \\ https://hal.sorbonne-universite.fr/hal-02328885}

Submitted on 23 Oct 2019

HAL is a multi-disciplinary open access archive for the deposit and dissemination of scientific research documents, whether they are published or not. The documents may come from teaching and research institutions in France or abroad, or from public or private research centers.
L'archive ouverte pluridisciplinaire HAL, est destinée au dépôt et à la diffusion de documents scientifiques de niveau recherche, publiés ou non, émanant des établissements d'enseignement et de recherche français ou étrangers, des laboratoires publics ou privés. 
Vessel Identifications Tags for Open or Laparoscopic Associating Liver Partition and Portal Vein Ligation for Staged Hepatectomy

Raffaele Brustia, MD; Olivier Scatton, MD, PhD; Fabiano Perdigao, MD; Sanaa ElMouhadi, MD; François Cauchy, MD; Olivier Soubrane, MD

Department of hepatobiliary and liver transplantation surgery, Hôpital Saint Antoine, Assistance publique-Hopitaux de Paris, Université Pierre et Marie Curie, Paris, France.

Corresponding author: Olivier Soubrane

$$
\begin{aligned}
& \text { Department of HPB surgery and liver transplantation } \\
& \text { Hopital Saint-Antoine } \\
& 184 \text { rue du Faubourg Saint-Antoine, } \\
& \text { Paris } 75012 \text { Cedex } \\
& \text { Tel: + } 33 \text { (1) } 71.97 .00 .31 \\
& \text { Fax: + } 33 \text { (1) } 71.97 .01 .57 \\
& \text { E-mail: olivier.soubrane@sat.aphp.fr }
\end{aligned}
$$

\section{Surgical technique}

Key words: Associating Liver Partition and Portal Vein Ligation for Staged Hepatectomy; ALPPS; Two Staged Hepatectomy; Liver Surgery; Tapes; Postoperative Morbidity; Inflammatory Adhesion; Liver Hypertrophy; Tricks and Tips; Laparoscopic ALPPS

\section{The authors declare no conflict of interest}




\section{BACKGROUND}

Associating Liver Partition and Portal Vein Ligation for Staged Hepatectomy (ALPPS)

(1) has recently been proposed as the further evolution of "2Staged Hepatectomy" technique (2SHT). The first step consists in left clearance, right portal branch occlusion, in-situ splitting associated with middle hepatic vein section and deportalized liver left in-situ. During the second step, section of the right branch of hepatic artery, right portal vein and right bile duct are followed by right hepatectomy completion. Liver partition surgical trauma with right liver left in-situ, associated to portal vein ligation $(P V L)$, seems responsible of faster future remnant liver ( $F R L)$ hypertrophy (2). Enthusiastic small series reports described $80 \%$ up-to $200 \%$ FRL volume increase, allowing 9-to-15 days between the two steps (1,3-4). Far from being a harmless procedure, morbidity rate may be as high as $74 \%$ in original series, $52 \%$ of which Clavien-Dindo III-IV (1), and reported up-to $90 \%$ in other series, with high biliary fistula and death rates procedure-related (5-7). In classical 2SHT, the second step is often technically demanding due to fibrous adhesions, pedicular inflammation and anatomical atrophy/hypertrophy phenomena. The same adhesions, but less strong, are present during ALPPS second step. Changes concerning the shift towards an inflammatory pedicle and easily hemorrhagic dissection are enough to render this phase technically demanding. This surgical procedure is probably to be still considered in an early development phase, since standardisation of indications and surgical technique is lacking. In 2012 we described a new 2SHT technique: taping hilar structures with vessel loops during the first step allowed easier and faster identification of pedicular elements during the second step (8). We decided to introduce this technique, easy-to-perform and morbid-free, during ALPPS procedures. 


\section{METHODS}

\section{First step}

We proceed with FRL clearance (left liver or left lateral section), followed by liver parenchyma transection until the surface of inferior vena cava is reached. Hanging manoeuvre was performed only in case of right hepatectomy, with transection along the middle hepatic vein. The pedicular dissection is performed according to the pure Glissonian intrafascial approach (9): the right hepatic pedicle is dissected free and the right portal branch, right hepatic artery are isolated and taped. Each element is put on a colour-coded silastic vessel loop: blue for the right portal branch, red for the right hepatic artery (Figure 1A). The parenchymal transection is performed using an ultrasound dissector. When the hilar plate is reached, the right bile duct and hilar plate are dissected, and taped using a yellow vessel loop. When the middle hepatic vein is reached, the right portal branch is ligated and the middle hepatic vein is sectioned using a linear vascular stapler. The right liver is not mobilized for oncologic reasons (10). In order to avoid postoperative adhesions, a type-I acellular collagen membrane (Cova+Abdo, Biom'up, Lyon, France) is systematically used (figure 1B). An abdominal drain is eventually placed along the parenchymal transection surface.

\section{Interval}

A 7 to 10 days interval between the two procedures was planned. Liver function tests were routinely performed on postoperative days (POD) 1, 3, 5 and 7. A CT Scan was performed one week after $1^{\text {st }}$ step surgery to make sure that the FRL had increased in adequate proportion (Figure 2). The FRL/FLV ratio was expected to be at least $30 \%$ plan the $2^{\text {nd }}$ step of the procedure.

\section{Second step}


The approach was the same than the $1^{\text {st }}$ step (Laparoscopy/Laparotomy). After the removal of the acellular collagen membrane (figure $3 \mathrm{~A}$ ), and cautious removal of the inflammatory adhesions, we proceed with the identification of the silastic vessel loops (figure 3B). Ligation and section of the right hepatic artery and right bile duct were easily performed using these landmarkers. The right hepatic vein was dissected free and sectioned by application of a linear vascular stapler. The section of the right triangular ligament was the last step that completed right hepatectomy as usually done for an anterior approach.

\section{RESULTS}

From April 2012 to May 2013 we performed 6 ALPPS procedures. Details of the procedures are given in table 1 . The hanging manoeuvre was performed in $3 / 6$ patients: in two cases it was not performed because the scheduled procedure was a trisectionectomy with transection line along the falciform ligament, and the third case because under laparoscopy. In the remnant 3 cases the hanging manoeuvre was performed without inconvenient. One ALPPS was performed by pure laparoscopic approach for both steps, in a case of benign liver disease. According with the few cases described in the literature, the procedure is difficult, and careful patient selection is the key factor for success $(11,12)$. Even if adhesions were less important and easy to lyse, considered the difficulty represented by the procedure in itself with laparoscopy approach and the glissonian intrafascial pedicle dissection, we found that taping hilar structures was extremely useful.

The initial volumetry found a median FRL/FLV ratio of $21.0 \%$ (range $15.6 \%-22.2 \%$ ). After a mean interval of 8 days, the median FRL/FLV ratio increased to $30.0 \%$ (range $16.9-39.4 \%$ ), with a mean FRL hypertrophy of $43.0 \%$. This seems to be not higher than classical experience with PVL or portal vein embolization (13). The 
second step was faster than the first one (mean time 216 min vs 277 , respectively). Only one patient did not proceed to the second step, because of insufficient hypertrophy of the remnant liver (patient $n^{\circ} 5$ ) and is still alive, with stable metastatic disease. Two patients experienced biliary fistula (Clavien-Dindo III b) after the second step, responsible for a prolonged hospital stay (43 and 97 days). In both cases the bile leak were due to ischemic lesion of the left bile duct. Initially managed by ERCP, both cases were followed by percutaneous external-internal liver drainage because of non effectiveness; the drain were removed one month and five months later, respectively. Neither patient experienced liver failure nor died because of complications related to the procedure. One patient died from recurrence with multiple metastases in the liver, lung and peritoneum, 8 months after resection.

\section{COMMENTS}

Two Staged Hepatectomy has evolved through many technical refinements during the last two decades. From Makuuchi et al. (15), assessing the effectiveness of liver hypotrophy and FRL hypertrophy after PVE, passing trough the concept of $2 \mathrm{SHT}$ in surgery for liver metastasis (LM) (16), to reach the fusion of the two techniques: associating PVE to 2SHT with a 6 to 8 weeks interval (17) represents the actual standard of care for initially non resectable LM. The recently described ALPPS procedure seems to provide the same results with a faster and significant hypertrophy of the FRL. However, the surgical community has become rapidly aware that ALPPS is not immune from serious complications, which seemed to have disappeared years ago with the use of conventional $2 \mathrm{SHT}(5-7,14)$. The reason lies in the two major ALPPS drawbacks: the lack of definition of indications and standardization of the surgical technique. An international registry has recently been initiated, to draw conclusions about indications and outcomes (18). Although the 
original article is accurate on surgical details description and other groups proposed some tips and technical tricks $(1,2)$, the daily practice suggests new details refining to overcome the second ALPPS drawback. In our opinion, any strategy proposed to standardize the technique should be aware of the two following main points.

First, the second step surgery is technically challenging in both ALPPS and classical 2SHT. In the former, however, the liver transection surface reaching the inferior vena cava surface, adhesions are found to be more inflammatory than fibrous, making the pedicular re-dissection technically demanding.

Second, the non-completion of the second step, for instance in case of insufficient FRL or disease progression, should never be neglected. That is why any manoeuvre during the first step should be at a time useful towards the second step, but never irreversible, in case of no-return.

For this reason, we propose two technical tips during the first step, to proceed faster and to help achievement of the second step, in observance with the two abovementioned characteristics. The use of silastic vessel loops on the liver pedicle seems a valuable, rapid and morbid-free strategy: in our first description we demonstrated its utility without adverse effect during the classical 2SHT (8), so we decided to transfer it to the ALPPS technique. With the same goal, we employed a type-I acellular collagen membrane to limit adhesions (figure 1B, 2A), instead of the plastic bag described in the original article $(1,2)$. Because of inert characteristics of these materials, leaving them permanently in place along the liver transection surface is immune from short and long-term morbidity. It was therefore the case for a patient (patient \#5) in our short ALPPS series: she is still alive, with stable metastatic disease, acellular collagen membrane and vessel loops still left in place. 
Even if on a single patient, we found less adhesion in our laparoscopic case. Welldescribed and widely accepted benefits of laparoscopy, such minor parietal incisions, fewer foreign bodies, close environment, reduced and gentle manipulation of tissues and a close and humid environment with pneumoperitoneum, are probably among the factors responsible of such phenomena (19). Interestingly some authors evocate the role of pneumoperitoneum alone, before and after a pure open ALPPS procedure (20). In any case, due to the presence of punctual isolated experience, no conclusions can be drown. Results from the international ALPPS registry are attended. In conclusion we propose two easy-to-perform and morbid-free technical tips, to more easily overcome any "inflammatory" pitfall during ALPPS second step.

\section{REFERENCES}

(1) Schnitzbauer AA, Lang SA, Goessmann $\mathrm{H}$, et al. Right portal vein ligation combined with in situ splitting induces rapid left lateral liver lobe hypertrophy enabling 2-staged extended right hepatic resection in small-for-size settings. Ann Surg. 2012; 255:405-14.

(2) Alvarez FA, Ardiles V, Sanchez Claria R, Pekolj J, de Santibañes E. Associating Liver Partition and Portal Vein Ligation for Staged Hepatectomy (ALPPS): Tips and Tricks. J Gastrointest Surg. 2013;17:814-21.

(3) Donati M, et al. Combination of in situ split and portal ligation: lights and shadows of a new surgical procedure. Ann Surg. 2012;256:e11-2

(4) de Santibañes E et al. Our initial experience with ALPPS technique: encouraging results. Updates Surg. 2012;64:167-72.

(5) Dokmak S, Belghiti J. Which limits to the "ALPPS" approach? Ann Surg. 2012;256:e6 
(6) Narita M, Oussoultzoglou E, Ikai I, Bachellier P, Jaeck D. Right portal vein ligation combined with in situ splitting induces rapid left lateral liver lobe hypertrophy enabling 2-staged extended right hepatic resection in small-for-size settings. Ann Surg. $2012 ; 256: e 7-8$

(7) Aloia TA, Vauthey JN. Associating liver partition and portal vein ligation for staged hepatectomy (ALPPS): what is gained and what is lost? Ann Surg. 2012; 256:e9

(8) Scatton O, Katsanos G, Soubrane O. Two-stage hepatectomy: tape it and hang it, while you can. World J Surg. 2012;36:1647-50.

(9) Lortat-Jacob JL, Robert HG. Hepatectomie droite reglé. Press Med. 1952;60:549 $-551$

(10) Belghiti J, Guevara OA, Noun R, Saldinger PF, Kianmanesh R. Liver hanging maneuver: a safe approach to right hepatectomy without liver mobilization. J Am Coll Surg. 2001;193:109-11.

(11) Machado MA, Makdissi FF, Surjan RC. Totally laparoscopic ALPPS is feasible and may be worthwhile. Ann Surg. 2012;256:e13;

(12) Conrad C, Shivathirthan N, Camerlo A, Strauss C, Gayet B. Laparoscopic Portal Vein Ligation With In Situ Liver Split for Failed Portal Vein Embolization. Ann Surg. 2012;256: e14-e15

(13) Capussotti L, Muratore A, Baracchi F, et al. Portal vein ligation as an efficient method of increasing the future liver remnant volume in the surgical treatment of colorectal metastases. Arch Surg. 2008;143:978-82;

(14) Jain HA, Bharathy KG, Negi SS. Associating liver partition and portal vein ligation for staged hepatectomy: will the morbidity of an additional surgery be outweighed by better patient outcomes in the long-term? Ann Surg. 2012;256:e10; 
(15) Makuuchi M, Thai BL, Takayasu K, et al. Preoperative portal embolization to increase safety of major hepatectomy for hilar bile duct carcinoma: a preliminary report. Surgery. 1990;107:521-527

(16) Adam R, Laurent A, Azoulay D, et al. Two-stage hepatectomy: a planned strategy to treat irresectable liver tumors. Ann Surg. 2000;232:777-785.

(17) Jaeck D, Oussoultzoglou E, Rosso E, et al. A two-stage hepatectomy procedure combined with portal vein embolization to achieve curative resection for initially unresectable multiple and bilobar colorectal liver metastases. Ann Surg.

$2004 ; 240: 1037-1049$

(18) www.alpps.net

(19) Gutt CN, Oniu T, Schemmer P, et al. Fewer adhesions induced by laparoscopic surgery? Surg Endosc. 2004;18:898-906.

(20) Machado MA, Makdissi FF, Surjan RC. ALPPS procedure with the use of pneumoperitoneum. Ann Surg Oncol. 2013;20:1491-3 
Table 1

\begin{tabular}{|c|c|c|c|c|c|c|c|}
\hline Patient & 1 & 2 & 3 & 4 & 5 & 6 & mean \\
\hline Sex & $f$ & $\mathrm{~m}$ & $\mathrm{~m}$ & $f$ & $f$ & $f$ & - \\
\hline Age (years) & 56 & 46 & 66 & 45 & 67 & 59 & 56,5 \\
\hline Diagnosis & B-CRLM & $\mathrm{HCC}$ & B-CRLM & Poliadenomatosis & B-CRLM & B-CRLM & - \\
\hline Liver parenchyma & Neoadj CT & HBV hepatitis & Neoadj CT & Normal & Neoadj CT & Neoadj CT & - \\
\hline Approach 1st step & Open & Open & Open & Laparoscopy & Open & Open & - \\
\hline Duration (min) & 270 & 240 & 300 & 300 & 270 & 280 & 277 \\
\hline Hanging Manoeuvre & no & yes & no & no & yes & yes & $3 / 6$ \\
\hline 1st FRL volumetry (ml) & 343 & 470 & 337 & 380 & 220 & 276 & 337,7 \\
\hline 1st FRL/FLV (\%) & 18.6 & 15.6 & 21 & 22.2 & 12.8 & 20.7 & 21,0 \\
\hline Interval (days) & 9 & 10 & 9 & 7 & 7 & 7 & 8,2 \\
\hline Approach 2nd step & Open & Open & Open & Laparoscopy & - & Open & - \\
\hline Duration (min) & 240 & 180 & 120 & 300 & - & 240 & 216 \\
\hline 2nd FRL volumetry (ml) & 558 & 674 & 447 & 673.5 & 290 & 410 & 475,8 \\
\hline 2nd FRL/FLV (\%) & 30.6 & 22.3 & 30 & 39.4 & 16.9 & 31.5 & 30,0 \\
\hline FRL hypertrophy (\%) & 62.7 & 43 & 32.6 & 77.2 & 31.8 & 48.5 & 43,0 \\
\hline Hospital Stay (days) & 14 & 43 & 97 & 15 & 7 & 14 & 31,7 \\
\hline Complications & - & Bile leak & Bile leak & - & - & - & - \\
\hline Dindo Clavien & - & IIlb & Illb & - & - & - & - \\
\hline Outcome & Alive & Alive & Deceased & Alive & Alive & Alive & - \\
\hline
\end{tabular}

Patients demographics and characteristics. Bilobar colorectal liver metastasis (B-CRLM), Future Remnant Liver (FRL), Full Liver Volume (FLV), HBV (Hepatitis B Virus), Neoadjuvant Chemotherapy (Neoadj CT). 


\section{Figure1.}

Intraoperative view at the end of the first step of ALPPS procedure

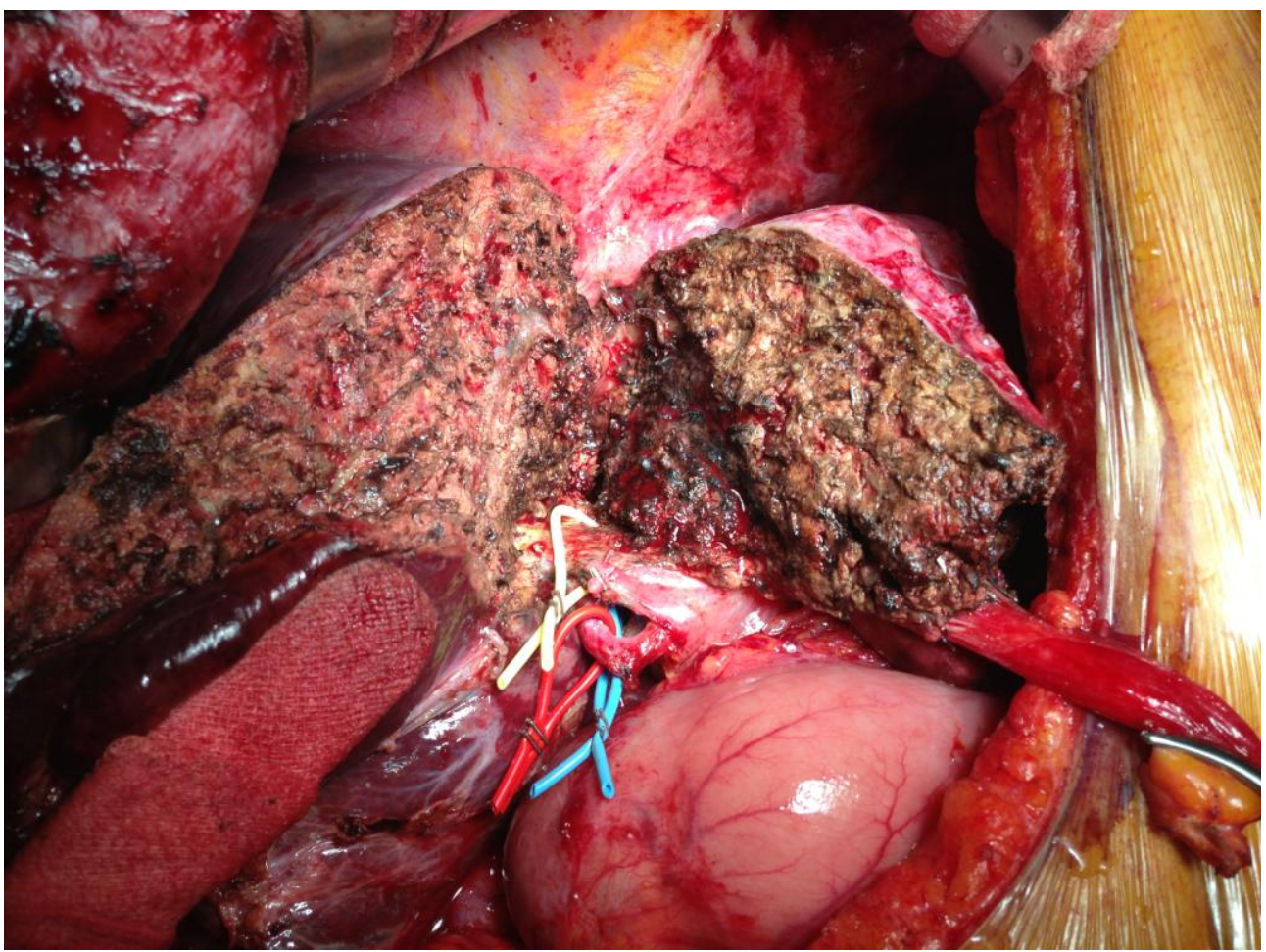

A. Color-coded vessel loops: yellow for right biliary duct, red for the right hepatic artery, blue for right branch of portal vein.

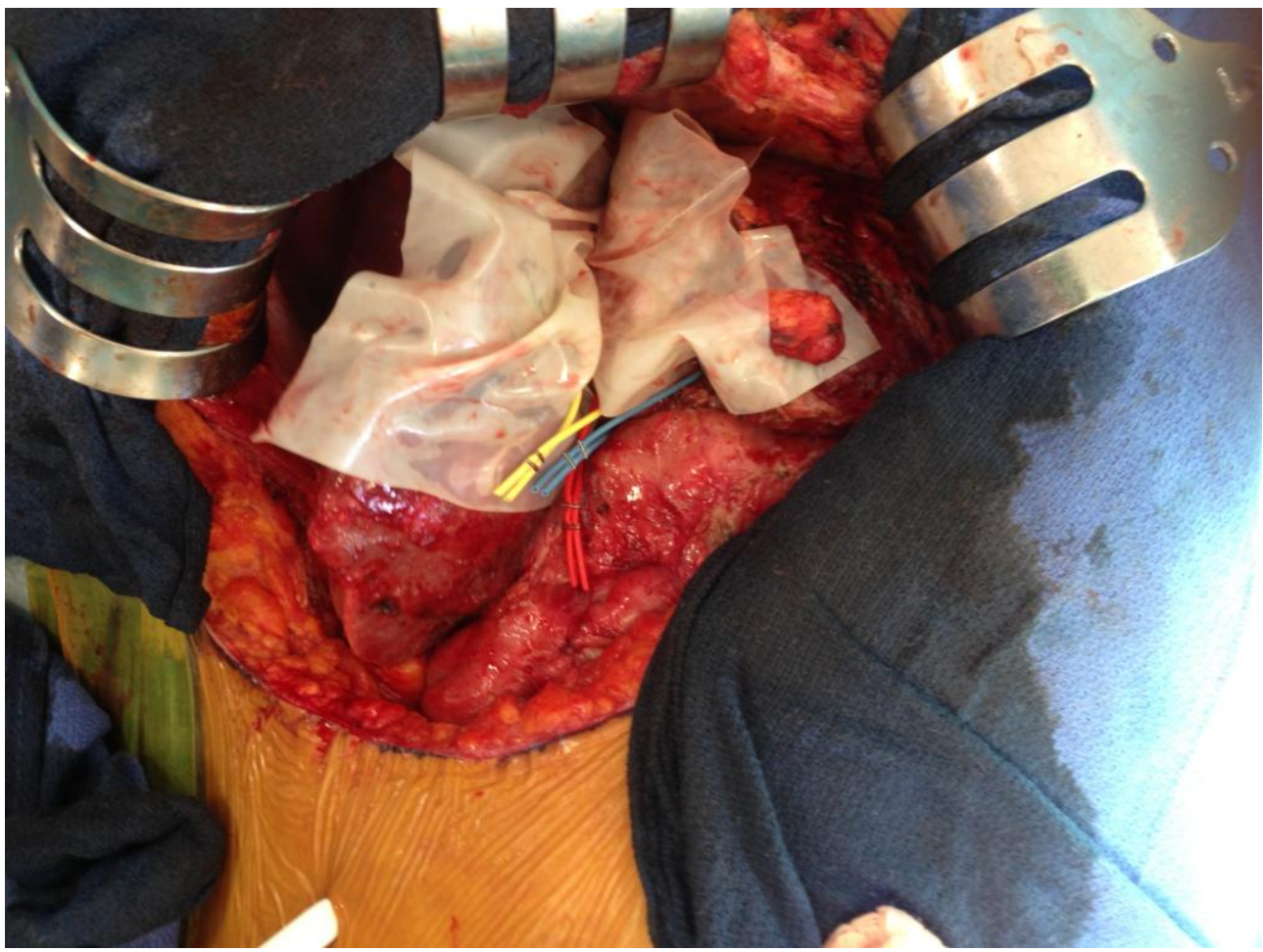

B. Acellular collagen membrane, to avoid adhesions, are shown. 
Figure 2.

POD 7 CT scan reconstructions.

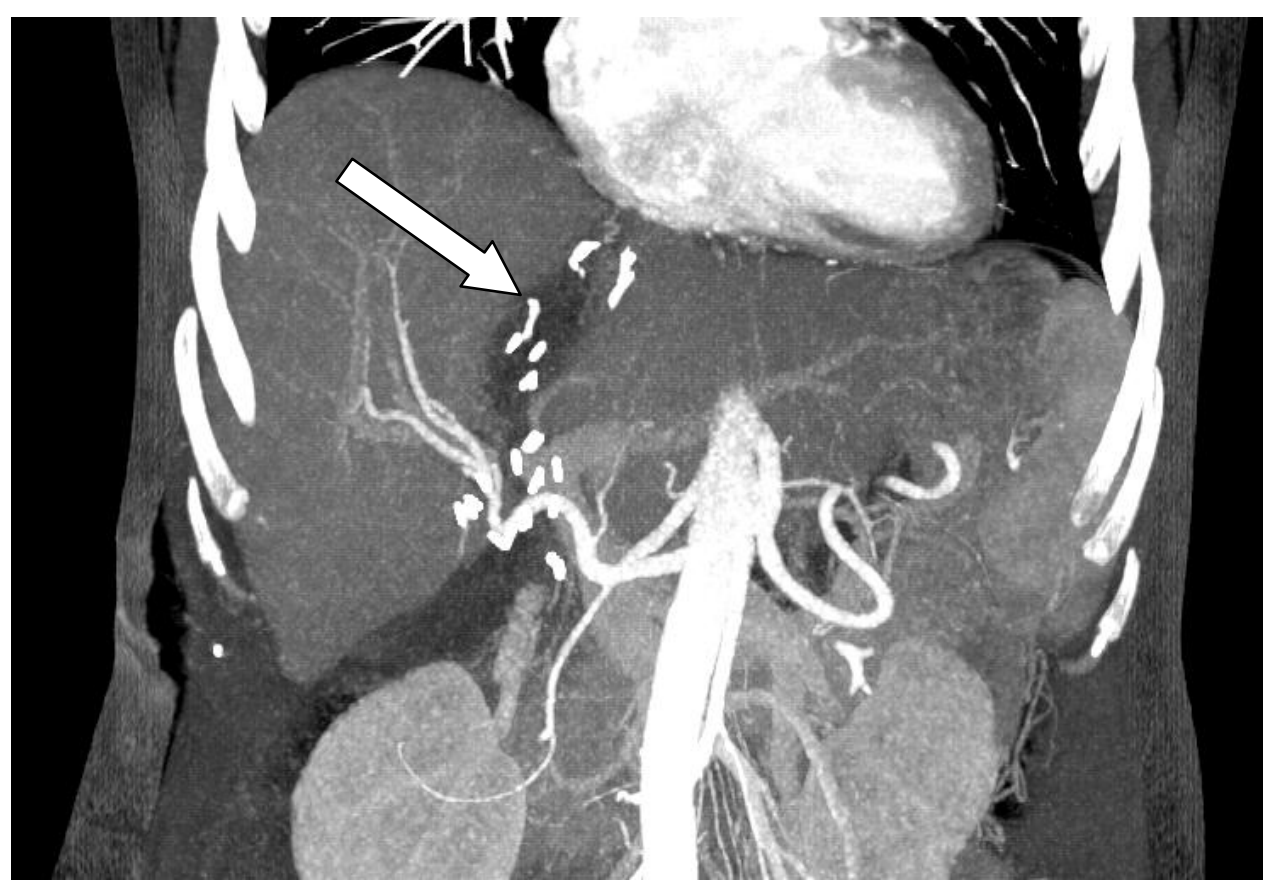

A. The liver transection line and the disconnection of the right portal vein is clearly seen (white arrow).

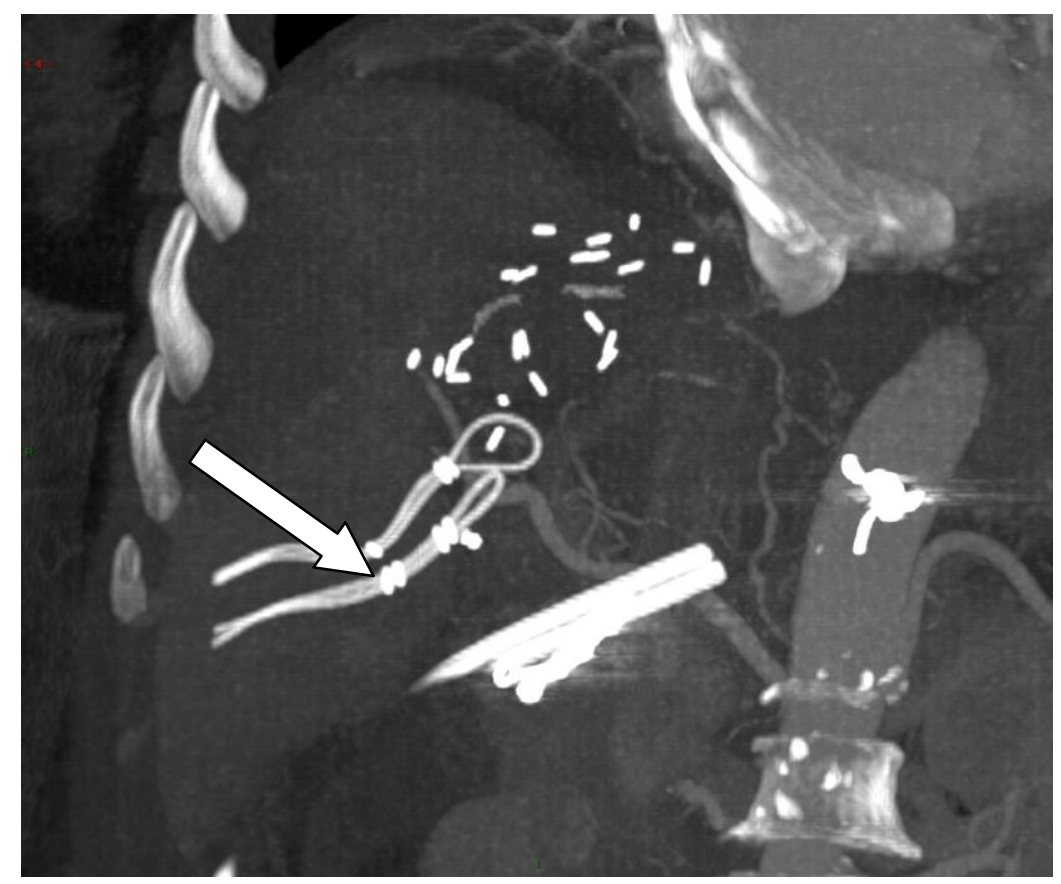

B Silastic vessel loops, and clips along the liver transection line (white arrow). 
Figure 3.

Intraoperative view of the ALPPS procedure, second step

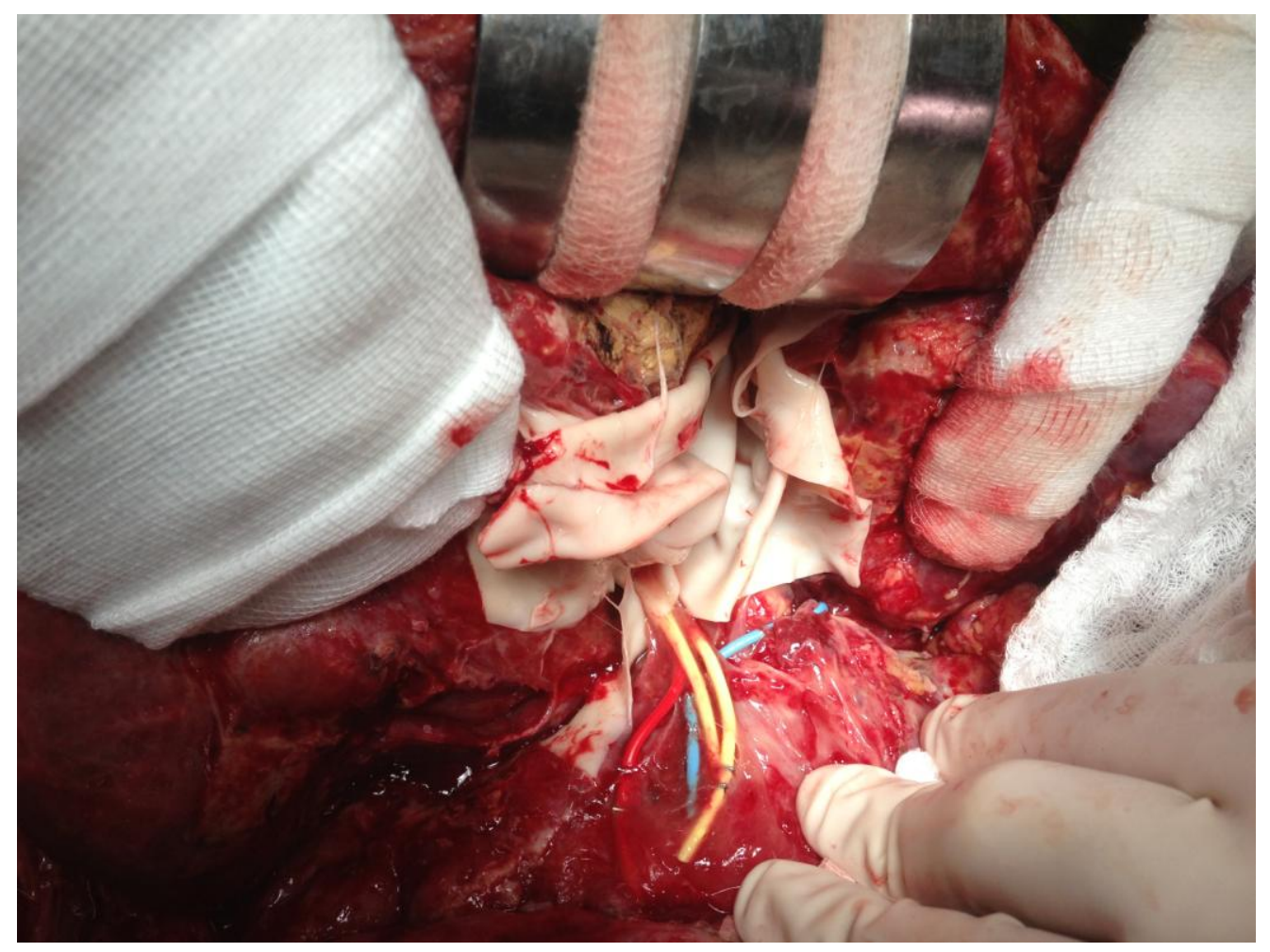

A. Vessel loops in place, inflammatory adhesions, covered by the anti-adhesion acellular collagen membrane.

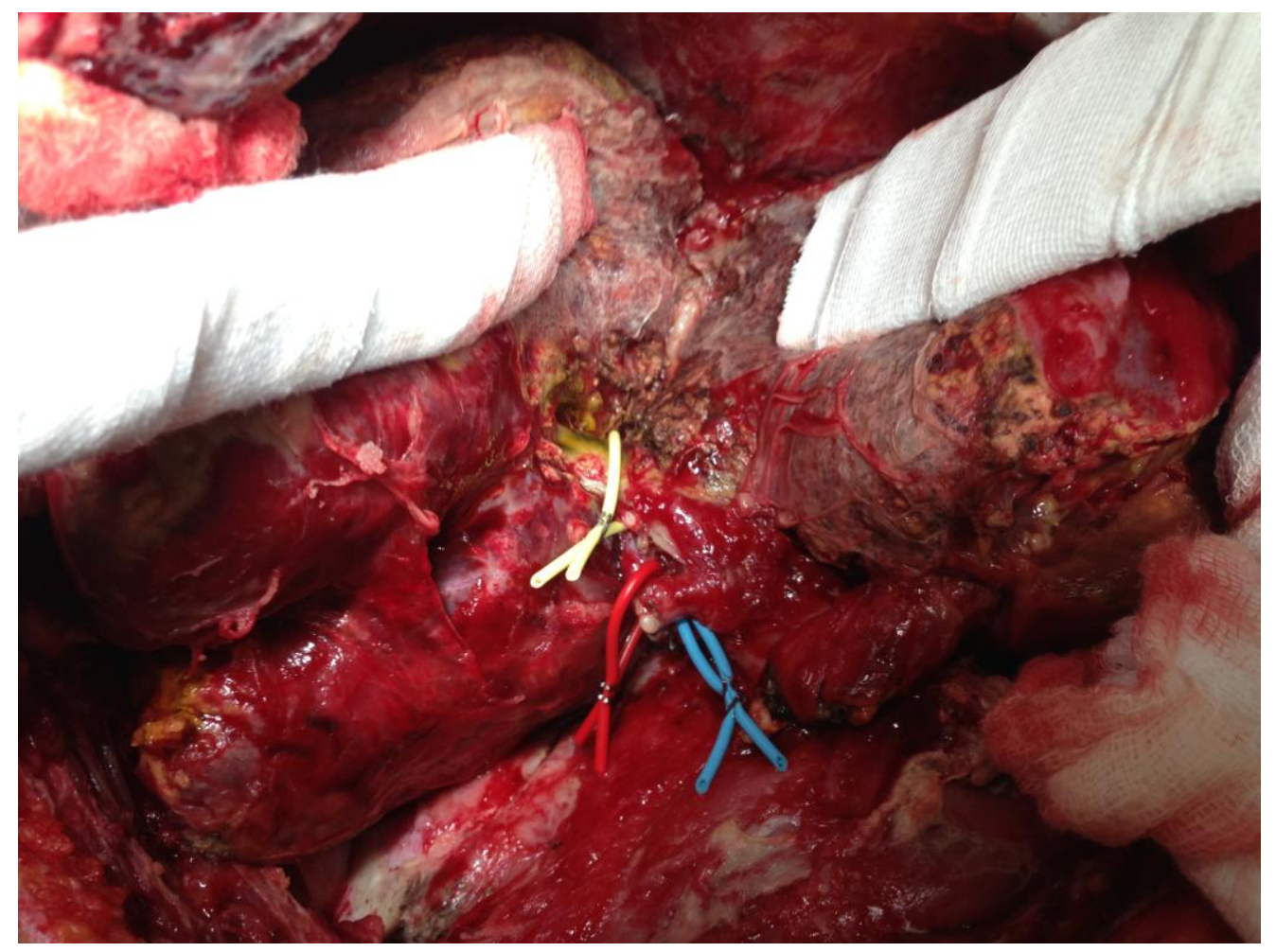


B. Removal of acellular collagen membrane; vessel loops are in place, and inflammatory adhesions are clearly visible. TachoSil sponge were disposed on the liver section surface at the end of the first step. 